\title{
RNA interference machinery-mediated gene regulation in mouse adult neural stem cells
}

Filippo M. Cernilogar ${ }^{1,2^{*}}$, Rossella Di Giaimo ${ }^{3,4}$, Frederick Rehfeld ${ }^{1,5}$, Silvia Cappello ${ }^{7}$ and D. Chichung Lie ${ }^{1,6}$

\begin{abstract}
Background: Neurogenesis in the brain of adult mammals occurs throughout life in two locations: the subventricular zone of the lateral ventricle and the subgranular zone of the dentate gyrus in the hippocampus. RNA interference mechanisms have emerged as critical regulators of neuronal differentiation. However, to date, little is known about its function in adult neurogenesis.
\end{abstract}

Results: Here we show that the RNA interference machinery regulates Doublecortin levels and is associated with chromatin in differentiating adult neural progenitors. Deletion of Dicer causes abnormal higher levels of Doublecortin. The microRNA pathway plays an important role in Doublecortin regulation. In particular miRNA-128 overexpression can reduce Doublecortin levels in differentiating adult neural progenitors.

Conclusions: We conclude that the RNA interference components play an important role, even through chromatin association, in regulating neuron-specific gene expression programs.

Keywords: RNAi, Dicer, Argonaute, Doublecortin, miRNA-128, Adult neurogenesis

\section{Background}

The precise regulation of proliferation, survival, migration and differentiation of neural stem cells (NSCs) and neural progenitors is crucial for proper formation of the mammalian brain during embryonic, postnatal and adult stages [1-5]. In the adult mouse brain, NSCs persist throughout life in the subgranular zone of the hippocampal dentate gyrus (DG) and the subventricular zone (SVZ) of the lateral ventricle. In these regions, NSCs generate mature neurons through a complex sequence of developmental steps including the division of a precursor cell and a multi-step process (proliferation, differentiation, migration, targeting, and synaptic integration) that ends with the formation of a postmitotic functionally integrated new neuron [6]. These developmental stages can be distinguished on the basis of the expression of stage-specific marker proteins including the microtubule

\footnotetext{
*Correspondence: filippo.cernilogar@med.uni-muenchen.de

${ }^{2}$ Biomedical Center, Ludwig Maximilian University, Großhaderner Strasse

9, 82152 Planegg-Martinsried, Germany

Full list of author information is available at the end of the article
}

binding protein Doublecortin (Dcx). In the adult mouse brain, Dcx is almost exclusively expressed by immature newborn neurons in the DG and the SVZ/Olfactory Bulb-system and is commonly used to distinguish immature neurons from non-neuronally committed precursors and to estimate neurogenic activity [7-10]. Perturbation of adult neurogenesis is associated with learning memory deficits, dysregulation of mood, and has been implied in the pathogenesis of neuropsychiatric disorders [11, 12]. Hence, revealing the regulation of genetic programs crucial for NSCs expansion and lineage commitment in the adult brain can provide the molecular basis for developing effective methods for NSC-based and adult neurogenesis-targeted therapies.

RNA interference (RNAi) mechanisms are a well-conserved phenomenon in eukaryotes and act at multiple levels to regulate gene expression [13-16]. A large number of small RNA classes have been identified, including microRNAs (miRNAs), small interfering RNAs (siRNAs) and Piwi-interacting RNAs (piRNAs). These classes differ in their biogenesis, their modes of target regulation 
and in the biological pathways they regulate [17-19]. In mammals small RNA silencing pathways depend on two groups of genes encoding the key proteins of the Dicer and Argonaute families [18].

The RNase III enzyme Dicer is required for the processing of short (21-22 nucleotides) micro-RNAs (miRNAs) and small interfering RNAs (siRNAs) from double stranded RNA precursors. Dicer-generated RNAs trigger the degradation of complementary mRNAs or prevent their translation [13-15]. In addition accumulating evidence indicates that RNAi components and small RNAs participate in nuclear processes such as transposon regulation, heterochromatin formation, genome stability and transcription [20-23]. Defining the role of Dicer generated small RNAs in mammalian development is complicated by embryonic lethality of constitutive Dicer knockouts in mice [24, 25]. Mouse embryonic stem cells in the absence of Dicer fail to differentiate in vitro and do not contribute to mouse development in vivo [26]. This highlights the importance of siRNAs and miRNAs in the regulation of gene expression during cell differentiation.

Here we show that the RNAi machinery regulates Dcx levels and is associated with chromatin in differentiating adult neural progenitors. Deletion of Dicer causes abnormal higher levels of Dcx expression and miRNA128 over-expression can down-regulate Dcx levels in differentiating adult neural progenitors. In addition a chromatin-binding assay reveals that some of Dicer and Argonaute-2 associate to chromatin in differentiating adult neural progenitors. We conclude that the Dicer/ Argonaute-2 RNAi pathway plays an important role, potentially even through chromatin association, in regulating gene expression programs in the neural stem cell lineage.

\section{Results}

\section{Adult neural stem cells lacking Dicer have higher level of Doublecortin}

To study RNAi machinery function in mouse adult neural stem cells we isolated neural progenitor cells (NPCs) from the SVZ of 8 weeks old Dicer cKO (Dicer ${ }^{\text {flox/flox }}$ ) mice [27]. The deletion of the LoxP-flanked exons 20-21 in the Dicer locus was induced by transducing NPCs with the HTN-Cre protein, a recombinant fusion protein able to cross the cell and nuclear membrane [28]. Consistent with the almost complete deletion of the Dicer locus (Additional file 1: Fig. S1A) the HTN-Cre treated cells showed a marked decrease in the levels of mature miRNAs (Fig. 1a), of Dicer transcript (Fig. 1b), and of Dicer protein (Fig. 1c) indicating that activity of the RNAi machinery was severely impaired. Along with the Dicer transcript we analyzed the levels of additional transcripts (Fig. 1b), namely Actin as a housekeeping gene, Lin41

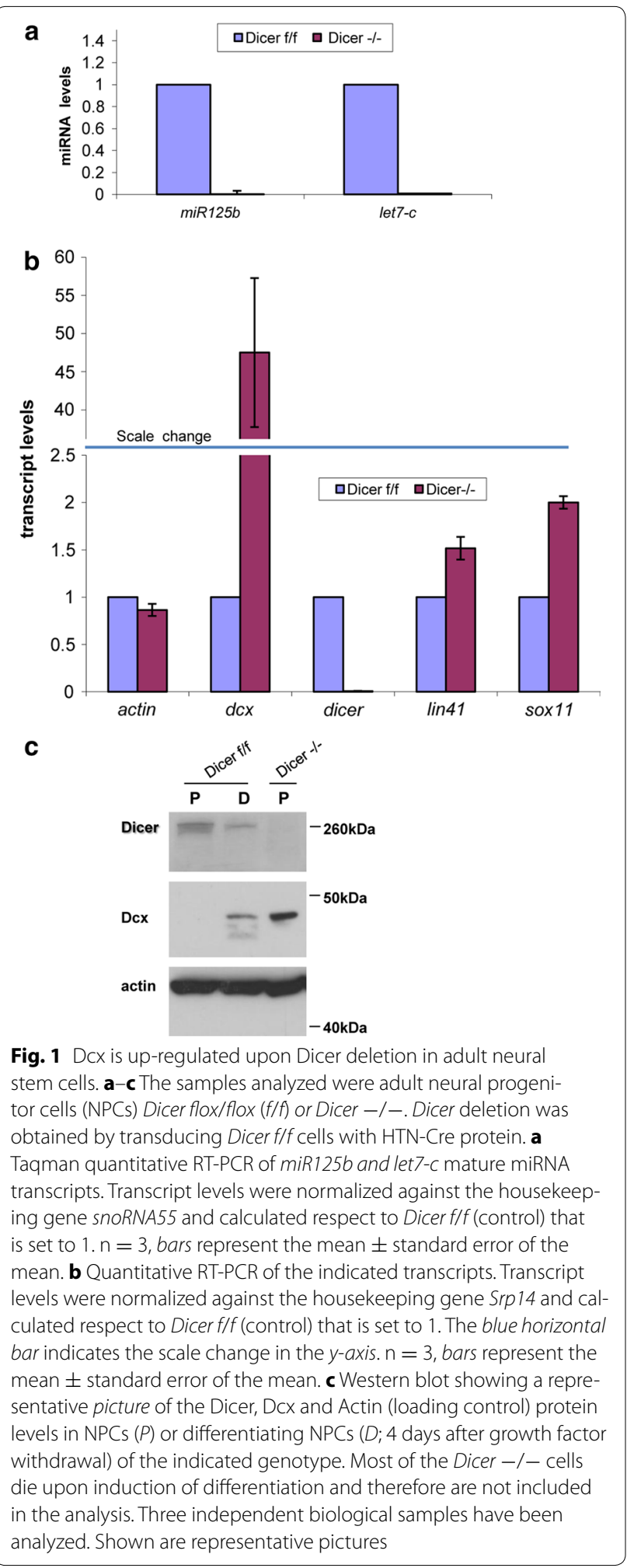

as miRNA-dependent gene [29], Dcx and Sox11 as possible miRNA targets based on the miRNA target prediction algorithm TargetScan [30]. The Actin transcript 
levels were almost unchanged; Lin41 and Sox11 transcripts were slightly up-regulated, but strikingly $D c x$ showed a 47.5 ( \pm 9.7 SEM) fold increase in Dicer null cells compared to control cells. Then we asked if the increase of the Dcx transcript in Dicer null cells resulted also in an increase of the Dcx protein level. In control NPCs, the Dcx protein was detectable only in differentiating cells (Fig. 1c) but, consistent with the qPCR data, the Dicer -/- NPCs had already detectable Dcx protein. Most of the Dicer -/- NPCs die upon induction of differentiation and therefore this condition was not included in the further analysis.

Overall our results show that in NPCs the ablation of Dicer and the consequent impairment of the RNAi machinery result in the up-regulation of the Dcx transcript and protein.

\section{Doublecortin is upregulated upon Dicer deletion in hippocampal newborn neurons}

In order to understand if the RNAi machinery impairment can deregulate Dcx expression also in the in vivo context we induced Dicer deletion in the adult hippocampal neurogenic lineage by injecting adult (8 weeks old) Dicer cKO (Dicer ${ }^{\text {flox/flox }}$ ) mice with a recombinant mouse moloney leukemia-retrovirus bicistronically encoding for GFP and Cre-recombinase into the septal hippocampal dentate gyrus. Heterozygous Dicer $c K O\left(\right.$ Dicer $\left.^{\text {flox/+}}\right)$ mice injected with the same retroviral preparation served as controls. Animals were sacrificed at 28 days post injection (dpi). Brain sections were immunostained for the immature neuronal marker Dcx and for GFP, to identify virustransduced cells (Fig. 2a, b). Consistent with previous studies most of virus-transduced cells in heterozygous Dicer cKO readily down regulated Dcx at $28 \mathrm{dpi}$ $[31,32]$. Interestingly, we found a significant increase (Fig. 2c) of Dcx/GFP double-positive cells in the Dicer $c K O$. We also checked another immature neuronal marker, Sox11, but did not observe significant differences of Sox11/GFP double positive cells in the Dicer cKO respect to the control (control: $49.6 \% \pm 11.3$ SEM; Dicer cKO: $63.9 \% \pm 9.7 \mathrm{SEM}$; $\mathrm{n}=4$, two-tailed $t$ test $\mathrm{p}=0.4$ ). The lack of significant change in Sox 11 expression is in line with our in vitro analysis (Fig. 1b) where Dicer - / - NPCs show minor increase in Sox11 expression. Additionally we observed a consistent reduction (about $40 \%$ ) of virally transduced GFP positve cells in the Dicer cKO (not shown). Although in the present experimental set up we cannot fully exclude differences in the virus transduction efficiency between different experimental groups this would be suggestive of reduced viability of Dicer deficient neurons. Taken together these data indicate that in newborn neurons
Dcx levels are sensitive to the levels of Dicer and thus to the functionality of the RNAi machinery.

\section{Overexpression of miRNA-128 reduces Doublecortin levels in differentiating adult neural stem cells}

Our in vitro and in vivo (Figs. 1,2) experiments show that the impairment of the RNAi machinery through the deletion of Dicer in NPCs is paralleled by abnormally elevated levels of Dcx. The Dcx transcript has been shown to be regulated by the RNAi machinery through miRNAdependent pathways that are severely reduced upon Dicer deletion (Fig. 1a). Specifically, miR-134 [33] was shown to regulate Dcx in mouse embryonic brain tissues, while miR-128 [34] was found to modulate Dcx levels in a human neuroblastoma cell line. Of these, we found only miR-128 to be expressed in adult mouse NPCs (Additional file 2: Fig. S2) in agreement with a previous report [35] showing the presence of miR-128 but not miR-134 in the neurogenic areas of the mouse adult brain. We next asked whether miR-128 could target and regulate Dcx levels in adult NPCs. To this purpose we created a miR128-RFP expression vector (see "Methods"). To check its functionality we transfected this vector into Neuro2A cells, which resulted in a marked increase in miR-128 levels (Fig. 3a) along with decreased levels of Dcx protein but not the transcript (Fig. 3b, c; Additional file 3: Fig. S3). This indicates that the vector is able to increase the miR-128 levels leading to Dcx down-regulation by translational repression as it has been described for many miRNAs [36]. We then transfected the miR-128-RFP or miR-Ctr-RFP (negative control containing a scrambled miRNA sequence) in adult NPCs (derived from the SVZ of 8-weeks old mice) and let them differentiate for 6 days. After fixation the cells were immunostained for Dcx, GFAP (a marker for astroglial cells) and RFP marking the transfected cells (Fig. 4a). Interestingly, we found a significant decrease in the fraction of Dcx positive cells among the transfected cells when miR-128 is overexpressed (Fig. 4b). Notably, the fraction of GFAP positive cells among the transfected ones was not significantly affected. Our results show that miR-128 overexpression reduces the levels of Dcx in differentiating NPCs indicating that miR-128 can target and potentially take part in the regulation of Dcx levels in adult neurogenesis.

\section{RNAi components are associated with chromatin in differentiating adult neural stem cells}

The RNAi machinery regulates gene expression mainly in the cytoplasm but has been reported to act also in the nucleus [20, 22, 23, 37, 38]. In order to assess if the main RNAi components could operate in the nucleus of NPCs we used a chromatin binding assay [23, 39] on undifferentiated and differentiating NPCs. This assay has been 


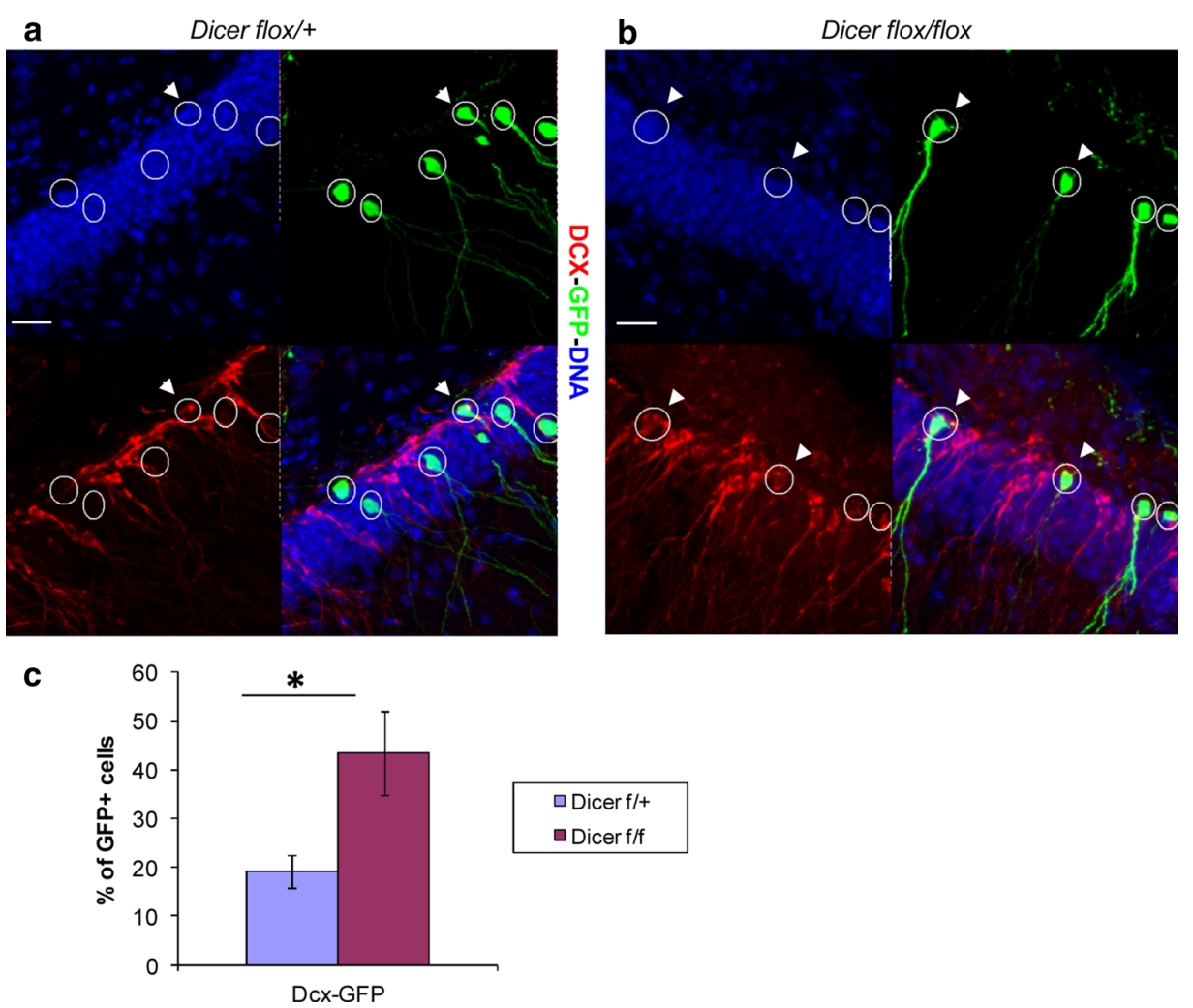

Fig. 2 Dcx is up-regulated upon Dicer deletion in hippocampal new born neurons. a, b Representative pictures of the immunostaining for Dcx and GFP on hippocampal regions of Dicer cKO mice transduced with Cre-recombinase. a Dicer flox/+ mice (control) $28 \mathrm{dpi}$. b Dicer flox/flox mice (experiment) $28 \mathrm{dpi}$. Transduced cells are GFP positive (green) and identified by white circles. Arrowheads indicate Dcx-expressing (red) among the Cre-transduced (green) cells. Single channel and overlay pictures are shown. Scale bar $25 \mu \mathrm{m}$. c Quantification of Dcx/GFP double positive cells among the virus-transduced cells. Bars show the average \pm the standard error of the mean $(n=4)$. At least 100 virus-transduced cells per group of four animals were analyzed. Two-tailed t test was applied for statistical analysis. Asterisks indicate statistically relevant differences; $p<0.05$

already used by us and others to predict the chromatin association of RNAi components [22, 23]. Chromatin associated proteins will be found in TritonX-100 resistant (P1) and, subsequently, in DNase and high salt (S2) extracted fractions (Fig. 5a). Indeed, a substantial portion of RNA Polymerase II (Pol II) is detected in these fractions (Fig. 5b). In contrast, most of Dicer and Argonaute-2 (Ago2) are found in the TritonX-100 soluble fraction (S1), along with $\beta$-catenin and glyceraldehyde 3-phosphate dehydrogenase (Gapdh), a marker for proteins not associated with chromatin (Fig. 5b). In differentiating NPCs (Fig. 5c) the markers Pol II and Gapdh are found in the same fraction as in undifferentiated cells. In contrast to undifferentiated NPCs, $\beta$-catenin was detected also in the chromatin fractions $(\mathrm{P} 1, \mathrm{~S} 2)$ consistent with the activation of the Wnt pathway during NPCs differentiation [40-42]. Interestingly, also Dicer and Ago2 display a differential fractionation profile depending on the differentiation status of the NPCs; thus Dicer and Ago2 were also found in the chromatin fraction P1 in differentiating NPCs. In contrast to Pol II and $\beta$-catenin,
Dicer and Ago2 are found almost exclusively in the P1 but barely in the S2 chromatin fraction indicating that TritonX-100 is sufficient to fully release these proteins most likely due to a looser chromatin association of Dicer and Ago 2 compared to Pol II and $\beta$-catenin.

Thus, the Dicer/Ago2 complex displays differential association with chromatin of adult NPCs depending on their differentiation status, raising the possibility that nuclear RNAi may contribute to the control of gene expression during specific developmental stages of adult neurogenesis.

\section{Discussion}

The RNAi machinery has emerged as an important regulator of neuronal differentiation but to date its contribution in adult neurogenesis is still not fully understood. We further probed the function of the RNAi machinery by loss-of-function, gain-of-function and biochemical approaches.

We show that in adult NPCs the ablation of Dicer results in a massive up-regulation of the Dcx transcript and 


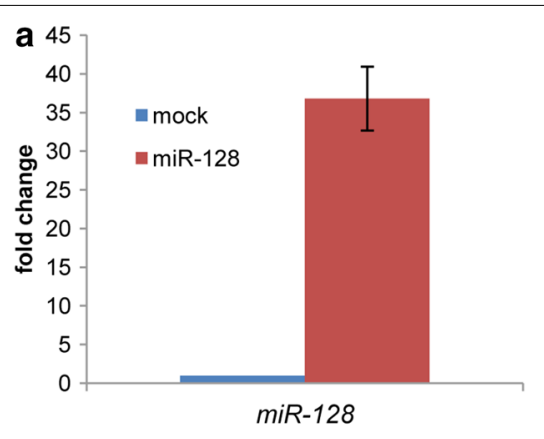

b
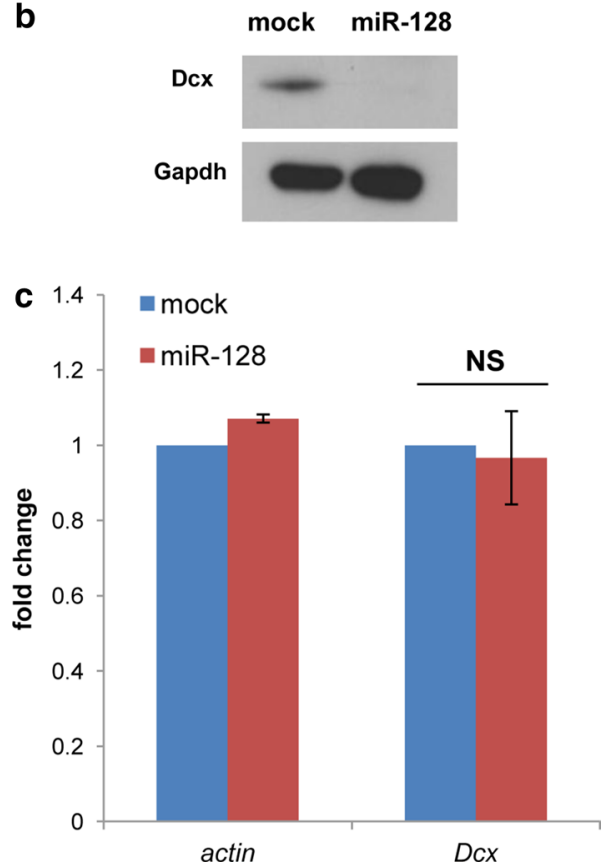

Fig. 3 Overexpression of miRNA128 reduces Dcx protein levels in N2A cells. a-c The samples analyzed were mock-treated Neuro2A cells (control transfection without miRNA-128-RFP expressing plasmid) or Neuro2A cells treated with miRNA-128-RFP expressing plasmid. a Taqman quantitative RT-PCR of the mature miRNA-128 transcripts normalized against the housekeeping small non-coding RNA snoRNA55. Transcript levels are indicated as fold change respect to the control (mock) that is set to $1 . \mathrm{n}=3$, bars represent the mean \pm standard error of the mean. $\mathbf{b}$ Western blot showing the Dcx and Gapdh (loading control) protein levels in mock and miRNA128 over-expressing cells. c Quantitative RT-PCR of the indicated transcripts. Transcript levels are indicated as fold change respect to the control (mock) that is set to 1. Transcripts were normalized against the housekeeping gene Srp14. $n=4$, bars represent the mean \pm standard error of the mean. Two-tailed t test was applied for statistical analysis. NS not significant; $p=0.4$

protein (Figs. 1, 2). This suggests that Dcx levels are heavily influenced directly or indirectly by RNAi activity. In favor of a direct regulation, $D c x$ mRNA has been shown to be targeted by different miRNAs [33, 34], which-in absence of Dicer-would not be matured and consequently would not be able to target $D c x$ mRNA for degradation or translational inhibition. In line with this view we show that overexpression of the miR-128 in differentiating adult NPCs causes the reduction of the Dcx levels (Fig. 4). However miR-128 and Dcx are not mutually exclusive in our in vitro cultured NPCs. Indeed miR-128 maintains similar level of expression also in differentiating NPCs (Additional file 2: Fig. S2) when Dcx is physiologically expressed (Fig. 1c). Like many miRNAs, miR-128 has been show to have relatively modest effects on its targets [43]. Thus, in differentiating NPCs, miR-128 is likely responsible to fine-tune rather than switching off Dcx, by repressing but without eliminating it. Notably the miRNA algorithm TargetScan (http://www.targetscan.org) identifies, in addition to miR128 , let-7 and miR-29 as potential regulators of Dcx. Both these miRNA are, similarly to miR-128, expressed in the neurogenic areas of the adult mouse brain [35] making them possible additional regulators of Dcx expression.

Argonaute directly binds the mature miRNA processed by Dicer and seeks target mRNAs that have complementarity to the miRNA. If complementarity exists in the central region of the miRNA (nucleotides 9-11) then the mRNA target can be cleaved via the endonuclease activity of Ago2. Differently Argonaute is recruited to a complex containing GW182 within cytoplasmic P bodies where translational repression occurs [36]. Notably miR128 lacks this complementarity (nucleotides 9-11) in $D c x$ target sites predicted by the miRNA algorithms TargetScan and microRNA.org [44] (http://www.microrna.org). In agreement with this prediction we found only the Dcx protein but not the transcript being down regulated upon miR128 overexpression (Fig. 3). Therefore the massive up-regulation of the $D c x$ transcript observed in NPCs upon Dicer deletion (Fig. 1) is hardly explained only by a decrease of miRNAs targeting $D c x$ but it likely involves additional layers of RNAi-dependent regulation.

miRNAs have been implied in the modulation of differentiation and proliferation of adult NPCs [45-50]. We kept adult Dicer-null NPCs in culture for weeks without visible defects but we observed a massive cell death upon stimulation of differentiation by growth factor withdrawal (data not shown), arguing that in particular differentiating NPCs are highly dependent on Dicer. In line with a particular importance of Dicer for differentiating cells, previous studies [51, 52] showed that Dicer is strictly required for embryonic NPCs differentiation. The ability of Dicer-null NPCs to generate both neurons and glia was, however, restored by the reintroduction of Dicer, demonstrating that these cells were not irreversibly transformed despite the absence of Dicer and microRNAs [51]. Similarly, reintroduction of Dicer was able to rescue the differentiation impairment of mouse embryonic stem cells Dicer -/- [53]. The dependency of NPCs 

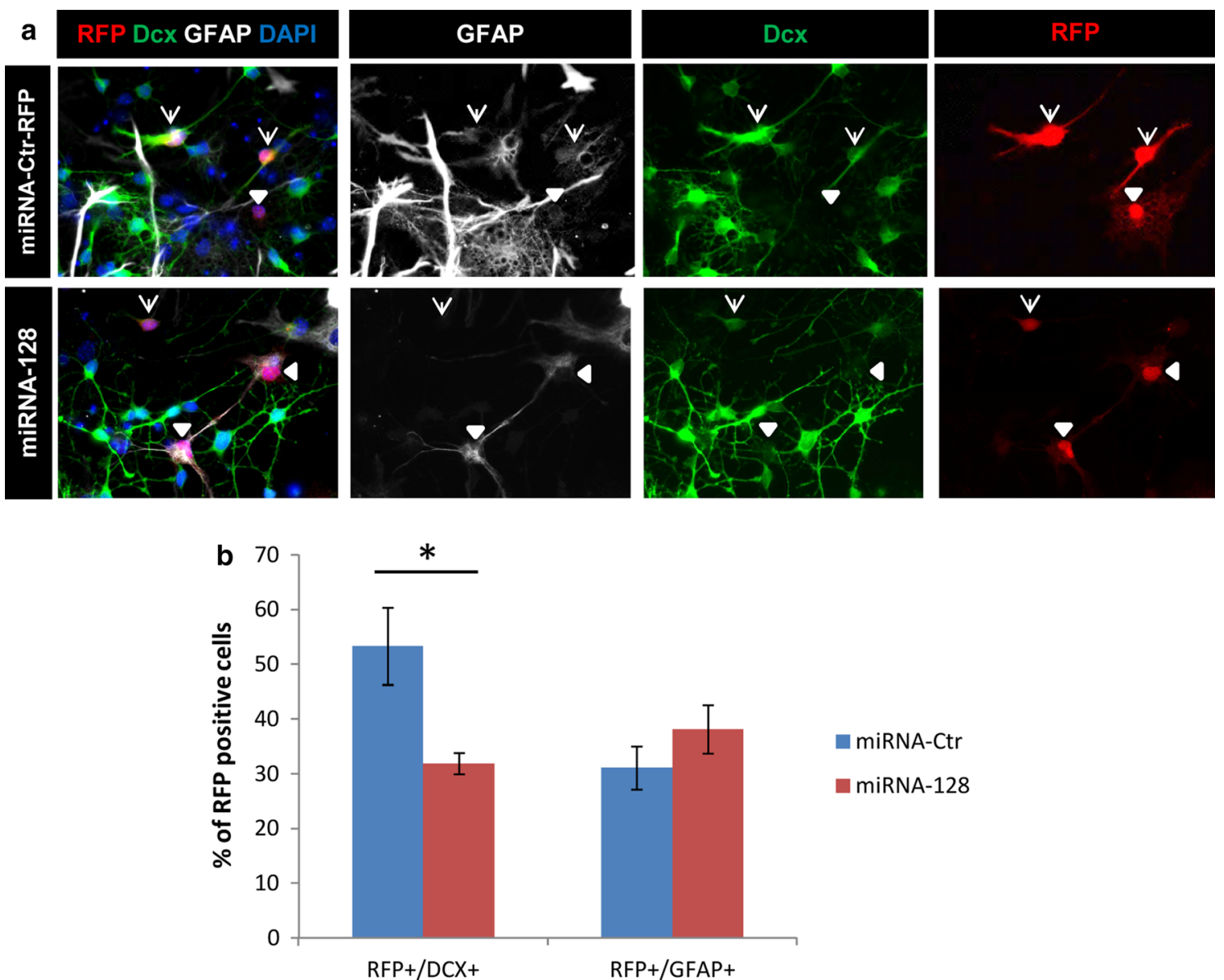

- miRNA-Ctr

miRNA-128

Fig. 4 Overexpression of miRNA128 reduces Dex protein levels in "in vitro" differentiating adult neural stem cells. a, b Adult neural progenitor cells were transfected with miRNA-Ctr-RFP (control) or mirRNA-128-RFP (experiment) expressing plasmids and induced to differentiate by growth factor withdrawal. Analysis was done 6 days later. a Representative pictures of the immunostaining of Dcx, GFAP and RFP on control and experiment cells. DAPI visualizes the DNA. Transfected cells are RFP positive. Arrows indicate Dcx/RFP positive cells; arrowheads indicate GFAP/RFP positive cells. b Quantification of Dcx and GFAP among the transfected cells. Bars show the average \pm the standard error of the mean $(n=3)$. The percentage of marker-positive cells among the total RFP-positive population was calculated on three biological replicates. At least 100 cells per experimental group were analyzed. Two-tailed t test was applied for statistical analysis. Asterisks indicate statistically relevant differences; $p<0.05$

differentiation on Dicer may not only be related to Dicer's crucial function in miRNA biogenesis. RNA interference components including Dicer have been implicated in nuclear related functions such as transposon regulation, heterochromatin formation, genome stability and transcription [20-23]. Notably, by using a chromatin binding assay we observed that some of the key RNAi components, Dicer and Argonaute-2, associate to chromatin in differentiating adult NPCs (Fig. 5). Although a ChIP-seq experiment (chromatin immunoprecipitation followed by next generation sequencing) will be required to reveal the Dicer and Ago-2 binding sites on chromatin, this already suggests that the critical role of RNAi in adult NPCs differentiation might be also linked to its chromatin-association.
Interestingly, transposable elements are expressed and active in the brain. LINE-1 elements, for example, are actively mobilized in normal mammalian brains during neurogenesis [54-56], leading to genetic heterogeneity, which might be of functional relevance. However, because transposable elements are capable of jumping into new positions in the genome they are potentially detrimental. Transposable element activation has been correlated with several neurodegenerative diseases [57-64]. Interestingly it has been recently shown that mutations in the RNAi key component Argonaute- 2 resulted in increased transposons expression in the Drosophila brain leading to detrimental effects such as accelerate memory impairment and shortened life span [65]. It is tempting to speculate that RNAi components might have a similar function in 


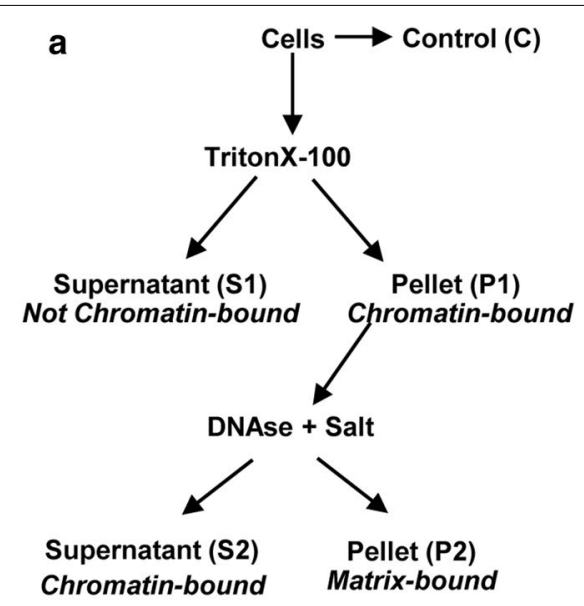

b

\section{Undifferentiated cells}

C S1 P1 S2 P2

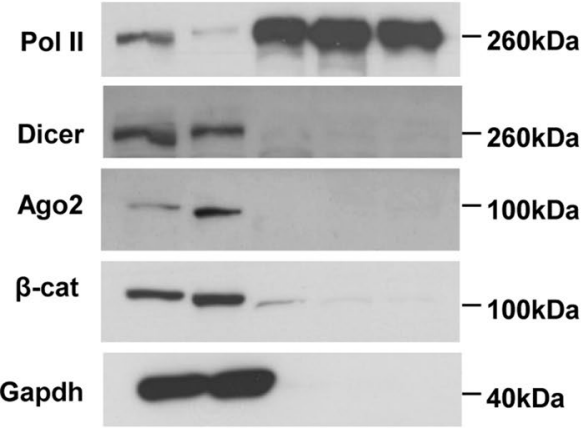

C Differentiating cells

C $\quad$ S1 1 P1 S2 P2

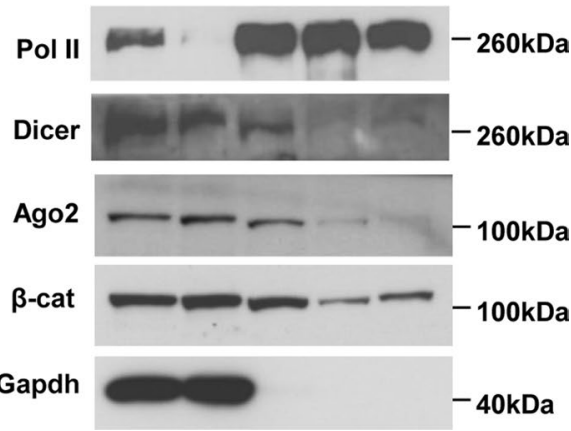

Fig. 5 RNAi components are associated with chromatin in differentiating adult neural stem cells. a Scheme of the procedure followed to fractionate neural progenitor cells. Insoluble fractions (pellets) were dissolved in RIPA buffer (see "Methods"). Chromatin associated proteins should be found in fractions P1 and S2. b, c Equivalent amounts of the resulting protein samples from undifferentiated or differentiating (3 days) adult neural progenitor cells were analyzed by western blot for the presence of the indicated proteins. Gapdh (glyceraldehyde 3-phosphate dehydrogenase) serves as a chromatin unbound marker; Pol II (RNA Polymerase II) is a chromatin bound marker. $\beta$-cat $\beta$-catenin, Ago 2 Argonaute- 2 . Three independent biological samples have been analyzed. Shown are representative pictures

the mammalian brain by acting as a barrier against excessive transposable element activity during neurogenesis.

\section{Conclusions}

Our data clearly show that RNAi machinery takes part in regulating neuron-specific developmental programs, in which the key RNAi components Dicer and Ago-2 display a dynamic chromatin association.

\section{Methods}

Animals

All experiments were performed in accordance with the European Communities Council Directive (86/609/EEC). Stereotactic injections of retroviruses into the brain of adult mice were approved by the Government of Upper Bavaria. According to German law, the approval of the animal experiments is given by a committee of the Government of Upper Bavaria, which checks (1) the conformity of the proposed study with German animal protection law, and (2) the relevance and ethical conformity. The relevant department in the Government of Upper Bavaria that issued the license for the experiments can be found at:

http://www.regierung.oberbayern.bayern.de/aufgaben/ umwelt/verbraucher/ansprech/.

8-12-week-old Dicer cKO [27] or C57BL/6 mice were used. Mice were grouped housed in standard cages under a $12 \mathrm{~h}$ light/dark cycle and had ad libitum access to food and water.

\section{Retrovirus preparation}

pCAG-GFP-IRES-Cre was generated from the pCAGGFP vector [66] by replacing the GFP coding sequence 
with cDNA for GFP and Cre recombinase as well as an internal ribosomal entry site (IRES). Retroviruses were generated as described previously [67]. Virus-containing supernatant was harvested four times every $48 \mathrm{~h}$ after transfection and concentrated by two rounds of ultracentrifugation. The obtained viral titers ranged between $10^{5}$ and $10^{8}$ colony forming units $(\mathrm{cfu}) / \mathrm{ml}$, dependent on the harvest number and the construct.

\section{Stereotactic injections}

All experiments were conducted under the condition that animals have ad libitum access to a running wheel until day 6 post injection. This measure was necessary to enhance proliferation and thus the number of transduced cells. Mice were deeply anesthetized with a mixture of fentanyl ( $0.05 \mathrm{mg} / \mathrm{kg}$ bodyweight), midazolam $(5 \mathrm{mg} / \mathrm{kg}$ bodyweight) and medetomidine $(0.5 \mathrm{mg} / \mathrm{kg}$ bodyweight). Anaesthesia was reverted with a mixture of buprenorphine $(0.1 \mathrm{mg} / \mathrm{kg}$ bodyweight), atipamezole $(2.5 \mathrm{mg} /$ $\mathrm{kg}$ bodyweight) and flumazenil ( $0.5 \mathrm{mg} / \mathrm{kg}$ bodyweight). Mice were stereotactically injected with $1 \mu \mathrm{l}$ of the CAGGFP-IRES-Cre retroviruses (titer $1 \times 10^{8} \mathrm{cfu} / \mathrm{ml}$ ) into the left and right dentate gyrus (coordinates from bregma were $-1.9 \mathrm{~mm}$ anterior/posterior, $\pm 1.6 \mathrm{~mm}$ medial/lateral, $-1.9 \mathrm{~mm}$ dorsal/ventral from dura). Group size was $n=4$ mice for each experimental group.

\section{Tissue processing}

Mice were sacrified using $\mathrm{CO}_{2}$. They were perfused with PBS, pH 7.4, for $5 \mathrm{~min}$, followed by $4 \%$ paraformaldehyde (PFA) for $5 \mathrm{~min}$. Brains were removed and post fixed in $4 \%$ PFA for $12 \mathrm{~h}$ at $4{ }^{\circ} \mathrm{C}$ and were subsequently transferred to a $30 \%$ sucrose solution. Forty-micrometer-thick coronal brain sections were cut using a sliding microtome (Leica Microsystems). Brain sections were stored at $-20{ }^{\circ} \mathrm{C}$ in cryoprotectant solution $(0.05 \mathrm{M}$ phosphate butter, $25 \%$ ethylenglycol v/v, $25 \%$ glycerol $\mathrm{v} / \mathrm{v})$.

\section{Histology and counting procedures}

Sections were blocked in Tris buffered saline (TBS) supplemented with $3 \%$ normal donkey serum and $0.25 \%$ Triton X-100 for $60 \mathrm{~min}$. Brain sections were incubated in blocking solution containing the primary antibodies at the appropriate dilutions at $4{ }^{\circ} \mathrm{C}$ for $48 \mathrm{~h}$. Primary antibodies against the following antigens were used: Dcx (rabbit, 1:250; Abcam ab18723), GFP (chicken, 1:500; Aves Labs GFP-1020), Sox11 (goat, 1:500; Santa Cruz sc-17347). After three washes in TBS, samples were incubated in blocking solution containing the secondary antibody coupled to $\mathrm{Cy} 3, \mathrm{Cy} 5$ or FITC, for $2 \mathrm{~h}$ at room temperature. Secondary antibodies were obtained from
The Jackson Laboratory and were used at a dilution of 1:250 after resuspension in $200 \mu \mathrm{l}$ of $\mathrm{H}_{2} \mathrm{O}$ and $200 \mu \mathrm{l}$ of glycerol. Samples were washed three times with TBS, incubated in $10 \mathrm{mg} / \mathrm{ml}$ DAPI (4',6-diamidino-2-phenylindole; 1:10,000; Sigma-Aldrich) for $10 \mathrm{~min}$, and mounted in Aqua PolyMount (Polysciences). To characterize the phenotype of the retrovirally transduced cells, equidistant sections containing the dentate gyrus were selected and stained. Transduced cells were identified based on the expression of GFP and were analyzed by confocal microscopy for immunoreactivity of the respective markers $(n>100$ cells per group of at least four animals). The counting procedure was carried out blindly. Confocal single-plane images and $Z$-stacks were taken on a Leica SP5 confocal microscope.

\section{Cell culture}

Neural stem/progenitor cells were isolated from adult (8-12 weeks) hippocampal tissue or subventricular area using the protocol described in [68]. Cells were cultured on poly-D-lysine (PDL; $10 \mu \mathrm{g} / \mathrm{ml}$; Sigma) and laminin (5 $\mu \mathrm{g} / \mathrm{ml}$; Invitrogen) coated plates in DMEM/F-12 medium (Invitrogen) containing B27 supplement (Invitrogen), $8 \mathrm{mM}$ HEPES buffer, $1 \times$ penicillin/ streptomycin/fungizone (Invitrogen), $20 \mathrm{ng} / \mathrm{ml}$ epidermal growth factor (EGF; PeproTech), and $20 \mathrm{ng} / \mathrm{ml}$ basic fibroblast growth factor (FGF2; PeproTech). Cultures were supplemented with growth factors every other day. Differentiation was induced by growth factor withdrawal.

\section{Dicer deletion by HTN-Cre}

For deletion experiments, Dicer $c K O$ neural stem/progenitor cells were seeded on PDL/laminin-coated 6-well plates and after $6 \mathrm{~h}$ transduced with $1 \mu \mathrm{M}$ HTN-Cre protein [28]. At $18 \mathrm{~h}$ after transduction, growth medium was replaced and the cells expanded to reach the required amount. The Cre-mediated deletion of the Dicer locus was verified by DNA PCR using the following primer pairs: for Dicer-flox, forward 5'-CCATTTGCTGGAGTG ACTCTG-3' and reverse 5'-TAAATCTGGCAAGCGAG ACG-3' (product size about $400 \mathrm{bp}$ ); for Dicer- $\Delta$ : forward 5'-AGTAATGTGAGCAATAGTCCCAG-3' and reverse as Dicer-flox (it gives a product only in case of recombination, size is about $350 \mathrm{bp}$ ). PCR amplifications were carried out in presence of $5 \%(\mathrm{v} / \mathrm{v})$ dimethyl sulfoxide. Differentiation was induced by growth factor withdrawal and harvested for analysis 4 days later. For western blot $20 \mu \mathrm{g}$ of protein extract were analyzed. Proteins of interest were detected with the following antibodies: rabbit anti-Dicer [1:1000, kindly provided by Chrysi Kanellopoulou [26]; rabbit anti-Dcx (Abcam ab18723); rabbit anti-Actin (1:4000, Abcam ab8227)]. 


\section{miRNA-128 overexpression}

Neural stem/progenitor cells were isolated from the subventricular zone of 8 -weeks old C57BL/6 mice as previously described [69] with the only difference that FGF2 and EGF (Invitrogen) were added both at $20 \mathrm{ng} / \mathrm{ml}$ to the B27-supplemented culture medium. Cells were seeded on Matrigel-coated 24-well plates (BD Bioscience) at the density of $1.5 \times 10 \mathrm{e} 5$ cells per well and transfected $24 \mathrm{~h}$ later with a miRNA-128-RFP plasmid or a control miRNA-CtrRFP plasmid using Lipofectamine 2000 (Life Technologies; ratio DNA/lipofectamine 1:4). Differentiation was induced by growth factor withdrawal $24 \mathrm{~h}$ after transfection. Cells were harvested for analysis 7 days after transfection. Cultures were fixed with $4 \%$ PFA for $15 \mathrm{~min}$. Primary antibodies against the following antigens were used: DCX (guinea pig, 1:2000, Millipore AB5910), GFAP (mouse, 1:500; Sigma G3893). Primary antibodies were applied overnight at $4{ }^{\circ} \mathrm{C}$ in $10 \%$ serum, $0.5 \%$ Triton X-100 in PBS. Fluorescent secondary antibody was used according to the manufacturer's protocol (Jackson ImmunoResearch). Single-plane images were taken on a Zeiss Axioplan fluorescence microscope. The percentage of marker-positive cells among the total RFP-positive population was determined for three wells within three different biological replicates. Approximately from ten to twelve randomly selected fields were evaluated for each condition in each experiment ( $n>100$ cells per experimental group). The counting procedure was carried out blindly.

Neuro2A cells were grown in Opti-MEM medium (Life Technologies). Cells were seeded on 6-well plates and after $24 \mathrm{~h}$ transfected with or without miRNA-128-RFP plasmid using Lipofectamine 2000 (Life Technologies; ratio DNA/lipofectamine 1:4). Cells were harvested for analysis $48 \mathrm{~h}$ after transfection. For western blot $20 \mu \mathrm{g}$ of protein extract were analyzed. Proteins of interest were detected with the following antibodies: rabbit anti-Dcx (Abcam ab18723); mouse anti-Gapdh (1:000, clone 6C5, Santa Cruz 32233).

\section{Dcx knock-down}

Neuro2A cells were grown in Opti-MEM medium (Life Technologies). Cells were seeded on $10 \mathrm{~cm}$ plates and after $24 \mathrm{~h}$ transfected with a shRNA-Dcx plasmid or a control shRNA-Ctr plasmid using Lipofectamine 2000 (Life Technologies; ratio DNA/lipofectamine 1:5). Cells were harvested for analysis $72 \mathrm{~h}$ after transfection. shRNA-expressing vectors were previously described [70]. For western blot $20 \mu \mathrm{g}$ of protein extract were analyzed. Proteins of interest were detected with the following antibodies: rabbit anti-Dcx (Abcam ab18723); rabbit anti-Actin (1:4000, Abcam ab8227).

\section{RNA isolation and RT-qPCR}

Total RNA was isolated using Trizol reagent (Invitrogen). cDNA was synthesized using QuantiTect Reverse Transcription Kit (Qiagen) including DNA elimination step. Real-time qPCRs were performed on a StepOne device (Applied Biosystems). Power SYBR Green PCR Master Mix (Applied Biosystems) was used for detection. Primers for qPCR were as follows: Sox 11 forward, 5'-CCC TGT CGC TGG TGG ATA AG-3' and reverse, 5'-GGT CGG AGA AGT TCG CCT C-3'; $D C X$ forward, 5'-TGC TCA AGC CAG AGA GAA CA-3' and reverse, 5'-CTG CTT TCC ATC AAG GGT GT-3'; Srp14 forward, 5'-CAG CGT GTT CAT CAC CCT CAA-3' and reverse, 5'-GGC TCT CAA CAG ACA CTT GTT TT-3'; Actin forward, 5' -TTG CTG ACA GGA TGC AGAAG-3' and reverse, $5^{\prime}$-ACA TCT GCT GGA AGG TGG AC-3'; Lin41 forward, 5'-CCC TTC TCC ATT CTC TCG GTG$3^{\prime}$ and reverse, 5'-AGA TGG GGA CAG AGC AGG TGT-3'; Dicer forward, 5'-AAT TGG CTT CCT CCT GGT TAT- $3^{\prime}$ and reverse, $5^{\prime}$-GTC AGG TCC TCC TCC TCC TC-3'; Sox2 forward, 5'-GCG GAG TGG AAA CTT TTG TCC- $3^{\prime}$ and reverse, $5^{\prime}$-CGG GAA GCG TGT ACT TAT CCT T-3'; Nestin forward, 5'-CCT TTC TTC TGT GGC TCA CC-3' and reverse, 5' ${ }^{\prime}$-TCA TCA TTG CTG CTC CTC TG-3'. Quantification was normalized to the housekeeping gene $\operatorname{Srp} 14$.

miRNA cDNA synthesis and amplification was performed with the TaqMan miRNA assay (Life Technologies) allowing the specific detection of the mature miRNA of interest. Real-time qPCRs were performed on the same StepOne device. Quantification in this case was normalized to the small noncoding genes snoRNA55 or snoRNA135. The IDs of the TaqMan Probe used were: miR-125 (000449); let7c (000379); miR-134 (001186); miR-128 (002216); snoRNA55 (001228); snoRNA135 (001230). Relative expression levels were calculated using the following equation: $\mathrm{A}=2[\mathrm{Ct}(\mathrm{ref})-\mathrm{Ct}$ (ref-control) $]-[\mathrm{Ct}($ sample $)-\mathrm{Ct}($ sample-control $)]$.

\section{miRNA overexpressing plasmids}

The generation of CAG-RFP-miRNA-IRES-RFP vectors was done as previously described [70]. Additionally the following miRNA128/cloning primers were used:

miRNA128 Fwd: 5'-TGCTG tca cag tga acc ggt ctc ttt GTT TTG GCC ACT GAC TGA CAA AGA GAC CTT CAC TGTGA-3'.

miRNA128 Rew: 5'-CCT GTCA CAG TGA AGG TCT CTT TGT CAG TCA GTG GCC AAAAC aaa gag acc ggt tca ctg tgaC-3' (in lower case is the mature miRNA128 sequence). 


\section{Chromatin binding assay}

The procedure was used essentially as previously described [23, 39]. Neural stem/progenitor cells $(7 \times$ confluent $10 \mathrm{~cm}$ plates of undifferentiated cells or $20 \times$ $10 \mathrm{~cm}$ plates of 3-days differentiating cells) were washed with cold PBS, detached from the plates with Accutase (Millipore), washed again with PBS and finally resuspended in $6 \mathrm{ml}$ of cold PBS. One tenth of the cell suspension (control fraction, C), was centrifuged at $400 \mathrm{~g}$ and resuspended in RIPA buffer [ $150 \mathrm{mM}$ Tris- $\mathrm{HCl}, \mathrm{pH}$ 8.0, $150 \mathrm{mM} \mathrm{NaCl}, 0.5 \%$ DOC, $0.1 \%$ (w/v) SDS, 1 \% (v/v) NP-40, Roche protease inhibitor cocktail] and left $30 \mathrm{~min}$ on ice. The remaining fraction was lysed for $15 \mathrm{~min}$ on ice in cold CSKI buffer [10 mM Pipes, $\mathrm{pH} 6.8,100 \mathrm{mM} \mathrm{NaCl}$, $1 \mathrm{mM}$ EDTA, $300 \mathrm{mM}$ sucrose, $1 \mathrm{mM} \mathrm{MgCl}_{2}, 1 \mathrm{mM}$ DTT, $0.5 \%(\mathrm{v} / \mathrm{v})$ Triton X-100, Roche protease inhibitor cocktail, $1 \mathrm{mM}$ PMSF]. The cell lysate was divided into two portions, which were centrifuged at $500 \mathrm{~g}$ at $4{ }^{\circ} \mathrm{C}$ for $3 \mathrm{~min}$. The supernatants ( $\mathrm{S} 1$ fraction), which contain Triton-soluble proteins, were further analyzed. One of the pellets was washed twice in CSKI buffer and then resuspended in RIPA buffer (the P1 fraction). The second pellet, after $2 \times$ CSKI washes, was resuspended in CSK II buffer (10 mM Pipes pH 6.8, $50 \mathrm{mM} \mathrm{NaCl}, 300 \mathrm{mM}$ sucrose, $6 \mathrm{mM} \mathrm{MgCl}_{2}, 1 \mathrm{mM}$ DTT, Roche protease inhibitor cocktail), treated with DNase for $30 \mathrm{~min}$ followed by extraction with $250 \mathrm{mM} \mathrm{NH}_{2} \mathrm{SO}_{4}$ for $10 \mathrm{~min}$ at $25^{\circ} \mathrm{C}$. The sample treated with DNase (Promega) and salt was then centrifuged at $1200 \mathrm{~g}$ for $6 \mathrm{~min}$ at $4{ }^{\circ} \mathrm{C}$ and the supernatant (S2 fraction), and pellet (P2 fraction), were collected. P2 after $2 \times$ washes in CSKII buffer was also resuspended in RIPA buffer. $20 \mu \mathrm{g}$ of all fractions were analyzed by immunoblotting. Proteins of interest were detected with the following antibodies: mouse anti-RNA Polymerase II (1:1000, clone 4H8, Abcam 5408); rabbit antiDicer [1:1000, kindly provided by Chrysi Kanellopoulou [26]; rat anti-Argonaute-2 (1:50; clone 6F4), kindly provided by Elisabeth Kremmer [71]; mouse anti- $\beta$-catenin (1:2000, BD Biosciences 610153); mouse anti-Gapdh (1:1000, clone 6C5, Santa Cruz 32233)].

\section{Additional files}

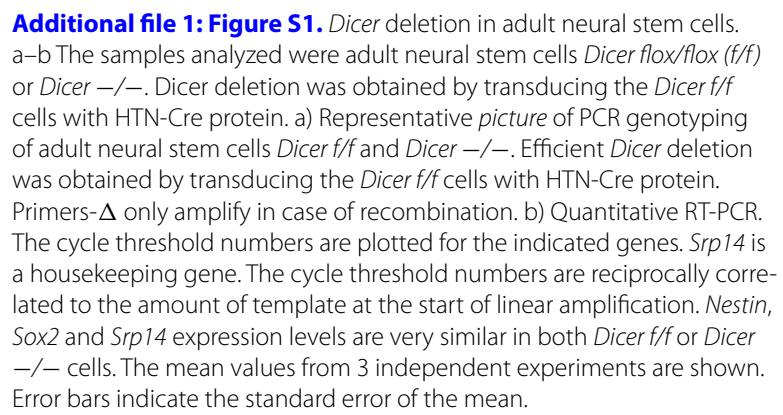

Additional file 2: Figure S2. miRNA-128 levels in adult neural progenitors cells. Shown is a Taqman quantitative RT-PCR on undifferentiated (undiff) or differentiating (diff; 4 days after growth factor withdrawal) adult neural progenitor cells. Levels of mature miR-128 were calculated as fold change relative to the housekeeping gene snoRNA55. $\mathrm{n}=3$, bars represent the mean \pm standard error of the mean. Three independent biological samples have been analyzed.

Additional file 3: Figure S3. miR128 over-expression reduces Dex protein in N2 cells. Western blot showing the Dcx (arrow) and Actin (loading control) protein levels in (from far right to left): mock (control transfection without miRNA-128-RFP expressing plasmid), miRNA-128 (cells treated with miRNA-128-RFP expressing plasmid), shRNA-Dcx (cells treated with shRNA targeting Dcx) and shRNA-Ctr (cells treated with control shRNA). The band corresponding to Dcx is reduced in both shRNA-Dcx and miR-128 samples. Dcx KD = Dcx knockdown; miR-128 OE = mirR-128 over-expression; $\mathrm{MW}=$ Molecular weight marker.

\section{Abbreviations}

SEM: standard error of the mean; ChIP-seq: Chromatin immunoprecipitation followed by next generation sequencing; NSCs: neural stem cells; DG: dentate gyrus; SVZ: subventricular zone; Dcx: Doublecortin; RNAi: RNA interference; miRNAs: microRNAs; siRNAs: small interfering RNAs; piRNAs: Piwi-interacting RNAs; dpi: days post injection; DAPI: 4',6-diamidino-2-phenylindole; PDL: polyD-lysine; FGF: fibroblast growth factor.

\section{Authors' contributions}

Conceived and designed the experiments: FMC, DCL. Performed the experiments: FMC, RDG. Analyzed the data: FMC, RDG, SC, DCL. Contributed reagents: FR. Wrote the paper: FMC, DCL. All authors read and approved the final manuscript.

\section{Author details}

${ }^{1}$ Research Group Adult Neurogenesis and Neural Stem Cells, Institute of Developmental Genetics, Helmholtz Center Munich, German Research Center for Environmental Health, Munich-Neuherberg, Germany. ${ }^{2}$ Biomedical Center, Ludwig Maximilian University, Großhaderner Strasse 9, 82152 Planegg-Martinsried, Germany. ${ }^{3}$ Institute for Stem Cell Research, Helmholtz Center Munich, German Research Center for Environmental Health, Munich-Neuherberg, Germany. ${ }^{4}$ Department of Biology, University of Naples Federico II, Naples, Italy. ${ }^{5}$ Present Address: Institute of Cell Biology and Neurobiology, Charité University, Berlin, Germany. ${ }^{6}$ Institute of Biochemistry, Emil Fischer Center, Friedrich-Alexander-Universität Erlangen-Nürnberg, Erlangen, Germany. ${ }^{7}$ Developmental Neurobiology, Max Planck Institute of Psychiatry, Munich, Germany.

\section{Acknowledgements}

We are grateful to Chrysi Kanellopoulou (NIH, Bethesda USA) and Elisabeth Kremmer (Helmholtz Zentrum München, Germany) for the Dicer and Argonaute-2 antibodies, respectively. We also thank Lifang Miu for help with stereotactic injections; Katharina Merz and Fabian Gruhn for help with tissue processing; Lucia Berti for help with isolation of neural progenitor cells; Kathrin Wassmer for retrovirus preparation. Funding was provided by Grants to D. C. L: the European Young Investigator Award of the European Science Foundation (DFG 858/6-3), the Bavarian Research Networks on Adult Neural Stem Cells "FORNEUROCELL" and on Human induced Pluripotent Stem Cells "FORIPS", the Helmholtz Alliance for Mental Health in an Ageing Society, the BMBF Network "Cell Based Regenerative Medicine", and the University Hospital Erlangen (IZKF Grants E12 and E16). The funders had no role in study design, data collection and analysis, decision to publish, or preparation of the manuscript.

\section{Compliance with ethical guidelines}

\section{Competing interests}

The authors declare that they have no competing interests.

Received: 11 October 2014 Accepted: 8 September 2015

Published online: 19 September 2015 


\section{References}

1. Kokovay E, Shen Q, Temple S. The incredible elastic brain: how neural stem cells expand our minds. Neuron. 2008;60(3):420-9.

2. Merkle FT, Alvarez-Buylla A. Neural stem cells in mammalian development. Curr Opin Cell Biol. 2006;18(6):704-9.

3. Perrier AL, Studer L. Making and repairing the mammalian brain-in vitro production of dopaminergic neurons. Semin Cell Dev Biol. 2003;14(3):181-9.

4. Zhao C, Deng W, Gage FH. Mechanisms and functional implications of adult neurogenesis. Cell. 2008;132(4):645-60.

5. Kriegstein A, Alvarez-Buylla A. The glial nature of embryonic and adult neural stem cells. Annu Rev Neurosci. 2009;32:149-84.

6. von Bohlen Und Halbach O. Immunohistological markers for staging neurogenesis in adult hippocampus. Cell Tissue Res. 2007;329(3):409-20.

7. Couillard-Despres S, Winner B, Schaubeck S, Aigner R, Vroemen M, Weidner N, Bogdahn U, Winkler J, Kuhn HG, Aigner L. Doublecortin expression levels in adult brain reflect neurogenesis. Eur J Neurosci. 2005;21(1):1-14.

8. Couillard-Despres S, Winner B, Karl C, Lindemann G, Schmid P, Aigner R, Laemke J, Bogdahn U, Winkler J, Bischofberger J, et al. Targeted transgene expression in neuronal precursors: watching young neurons in the old brain. Eur J Neurosci. 2006;24(6):1535-45.

9. Ming $\mathrm{GL}$, Song $\mathrm{H}$. Adult neurogenesis in the mammalian brain: significant answers and significant questions. Neuron. 2011;70(4):687-702.

10. Brown JP, Couillard-Despres S, Cooper-Kuhn CM, Winkler J, Aigner L, Kuhn HG. Transient expression of doublecortin during adult neurogenesis. J Comp Neurol. 2003;467(1):1-10.

11. Winner B, Kohl Z, Gage FH. Neurodegenerative disease and adult neurogenesis. Eur J Neurosci. 2011;33(6):1139-51.

12. Kheirbek MA, Klemenhagen KC, Sahay A, Hen R. Neurogenesis and generalization: a new approach to stratify and treat anxiety disorders. Nat Neurosci. 2012;15(12):1613-20.

13. Bartel DP. MicroRNAs: genomics, biogenesis, mechanism, and function. Cell. 2004;116(2):281-97.

14. Baulcombe D. RNA silencing in plants. Nature. 2004;431(7006):356-63.

15. Meister $G$, Tuschl T. Mechanisms of gene silencing by double-stranded RNA. Nature. 2004:431(7006):343-9.

16. Bantignies F, Cavalli G. Polycomb group proteins: repression in 3D. Trends Genet TIG. 2011;27(11):454-64.

17. Aravin AA, Hannon GJ, Brennecke J. The Piwi-piRNA pathway provides an adaptive defense in the transposon arms race. Science. 2007;318(5851):761-4.

18. Ghildiyal M, Zamore PD. Small silencing RNAs: an expanding universe. Nat Rev Genet. 2009;10(2):94-108.

19. Mello CC, Conte D Jr. Revealing the world of RNA interference. Nature. 2004;431(7006):338-42.

20. Castel SE, Martienssen RA. RNA interference in the nucleus: roles for small RNAs in transcription, epigenetics and beyond. Nat Rev Genet. 2013;14(2):100-12.

21. Li LC. Chromatin remodeling by the small RNA machinery in mammalian cells. Epigenet Off J DNA Methylation Soc. 2014;9(1):45-52.

22. Huang V, Zheng J, Qi Z, Wang J, Place RF, Yu J, Li H, Li LC. Ago 1 interacts with RNA polymerase II and binds to the promoters of actively transcribed genes in human cancer cells. PLoS Genet. 2013;9(9):e1003821.

23. Cernilogar FM, Onorati MC, Kothe GO, Burroughs AM, Parsi KM, Breiling A, Lo Sardo F, Saxena A, Miyoshi K, Siomi H, et al. Chromatin-associated RNA interference components contribute to transcriptional regulation in Drosophila. Nature. 2011;480(7377):391-5.

24. Bernstein E, Kim SY, Carmell MA, Murchison EP, Alcorn H, Li MZ, Mills AA, Elledge SJ, Anderson KV, Hannon GJ. Dicer is essential for mouse development. Nat Genet. 2003;35(3):215-7

25. Yang WJ, Yang DD, Na S, Sandusky GE, Zhang Q, Zhao G. Dicer is required for embryonic angiogenesis during mouse development. J Biol Chem. 2005;280(10):9330-5.

26. Kanellopoulou C, Muljo SA, Kung AL, Ganesan S, Drapkin R, Jenuwein T, Livingston DM, Rajewsky K. Dicer-deficient mouse embryonic stem cells are defective in differentiation and centromeric silencing. Genes Dev. 2005;19(4):489-501.

27. Cobb BS, Nesterova TB, Thompson E, Hertweck A, O'Connor E, Godwin J, Wilson CB, Brockdorff N, Fisher AG, Smale ST, et al. T cell lineage choice and differentiation in the absence of the RNase III enzyme Dicer. J Exp Med. 2005;201(9):1367-73.

28. Nolden L, Edenhofer F, Haupt S, Koch P, Wunderlich FT, Siemen H, Brustle $O$. Site-specific recombination in human embryonic stem cells induced by cell-permeant Cre recombinase. Nat Methods. 2006;3(6):461-7.

29. Ecsedi M, Grosshans H. LIN-41/TRIM71: emancipation of a miRNA target. Genes Dev. 2013;27(6):581-9.

30. Friedman RC, Farh KK, Burge CB, Bartel DP. Most mammalian mRNAs are conserved targets of microRNAs. Genome Res. 2009;19(1):92-105.

31. Jagasia R, Steib K, Englberger E, Herold S, Faus-Kessler T, Saxe M, Gage FH, Song $\mathrm{H}$, Lie DC. GABA-cAMP response element-binding protein signaling regulates maturation and survival of newly generated neurons in the adult hippocampus. J Neurosci Off J Soc Neurosci. 2009;29(25):7966-77.

32. Piatti VC, Davies-Sala MG, Esposito MS, Mongiat LA, Trinchero MF, Schinder AF. The timing for neuronal maturation in the adult hippocampus is modulated by local network activity. J Neurosci Off J Soc Neurosci. 2011;31(21):7715-28.

33. Gaughwin P, Ciesla M, Yang H, Lim B, Brundin P. Stage-specific modulation of cortical neuronal development by Mmu-miR-134. Cereb Cortex. 2011;21(8):1857-69.

34. Evangelisti C, Florian MC, Massimi I, Dominici C, Giannini G, Galardi S, Bue MC, Massalini S, McDowell HP, Messi E, et al. MiR-128 up-regulation inhibits Reelin and DCX expression and reduces neuroblastoma cell motility and invasiveness. FASEB J Off Publ Fed Am Soc Exp Biol. 2009;23(12):4276-87.

35. Bak M, Silahtaroglu A, Moller M, Christensen M, Rath MF, Skryabin B, Tommerup N, Kauppinen S. MicroRNA expression in the adult mouse central nervous system. RNA. 2008;14(3):432-44.

36. Hammond SM. An overview of microRNAs. Adv Drug Deliv Rev. 2015;87:3-14

37. Taliaferro JM, Aspden JL, Bradley T, Marwha D, Blanchette M, Rio DC. Two new and distinct roles for Drosophila Argonaute-2 in the nucleus: alternative pre-mRNA splicing and transcriptional repression. Genes Dev. 2013;27(4):378-89.

38. Gromak N, Dienstbier M, Macias S, Plass M, Eyras E, Caceres JF, Proudfoot NJ. Drosha regulates gene expression independently of RNA cleavage function. Cell Rep. 2013;5(6):1499-510.

39. Llano M, Vanegas M, Hutchins N, Thompson D, Delgado S, Poeschla EM. Identification and characterization of the chromatin-binding domains of the HIV-1 integrase interactor LEDGF/p75. J Mol Biol. 2006;360(4):760-73.

40. Lie DC, Colamarino SA, Song HJ, Desire L, Mira H, Consiglio A, Lein ES, Jessberger $\mathrm{S}$, Lansford $\mathrm{H}$, Dearie AR, et al. Wnt signalling regulates adult hippocampal neurogenesis. Nature. 2005;437(7063):1370-5.

41. Kuwabara T, Hsieh J, Muotri A, Yeo G, Warashina M, Lie DC, Moore L, Nakashima K, Asashima M, Gage FH. Wnt-mediated activation of NeuroD1 and retro-elements during adult neurogenesis. Nat Neurosci. 2009;12(9):1097-105.

42. Karalay O, Doberauer K, Vadodaria KC, Knobloch M, Berti L, Miquelajauregui A, Schwark M, Jagasia $R$, Taketo MM, Tarabykin V, et al. Prosperorelated homeobox 1 gene (Prox 1 ) is regulated by canonical Wnt signaling and has a stage-specific role in adult hippocampal neurogenesis. Proc Natl Acad Sci USA. 2011;108(14):5807-12.

43. Bruno IG, Karam R, Huang L, Bhardwaj A, Lou CH, Shum EY, Song HW, Corbett MA, Gifford WD, Gecz J, et al. Identification of a microRNA that activates gene expression by repressing nonsense-mediated RNA decay. Mol Cell. 2011;42(4):500-10.

44. Betel D, Wilson M, Gabow A, Marks DS, Sander C. The microRNA.org resource: targets and expression. Nucleic Acids Res. 2008;36(Database issue):D149-53.

45. Liu C, Teng ZQ, Santistevan NJ, Szulwach KE, Guo W, Jin P, Zhao X. Epigenetic regulation of miR-184 by MBD1 governs neural stem cell proliferation and differentiation. Cell Stem Cell. 2010;6(5):433-44.

46. Liu C, Teng ZQ, McQuate AL, Jobe EM, Christ CC, von Hoyningen-Huene SJ, Reyes MD, Polich ED, Xing Y, Li Y, et al. An epigenetic feedback regulatory loop involving microRNA-195 and MBD1 governs neural stem cell differentiation. PLoS One. 2013;8(1):e51436

47. Zhao C, Sun G, Ye P, Li S, Shi Y. MicroRNA let-7d regulates the TLX/microRNA-9 cascade to control neural cell fate and neurogenesis. Sci Rep. 2013;3:1329.

48. Zhao C, Sun G, Li S, Shi Y. A feedback regulatory loop involving microRNA-9 and nuclear receptor TLX in neural stem cell fate determination. Nat Struct Mol Biol. 2009;16(4):365-71. 
49. Sun G, Ye P, Murai K, Lang MF, Li S, Zhang H, Li W, Fu C, Yin J, Wang A, et al. miR-137 forms a regulatory loop with nuclear receptor TLX and LSD1 in neural stem cells. Nat Commun. 2011;2:529.

50. Cheng LC, Pastrana E, Tavazoie M, Doetsch F. miR-124 regulates adult neurogenesis in the subventricular zone stem cell niche. Nat Neurosci. 2009;12(4):399-408.

51. Andersson T, Rahman S, Sansom SN, Alsio JM, Kaneda M, Smith J, O'Carroll D, Tarakhovsky A, Livesey FJ. Reversible block of mouse neural stem cell differentiation in the absence of dicer and microRNAs. PLoS One. 2010;5(10):e13453.

52. Kawase-Koga Y, Low R, Otaegi G, Pollock A, Deng H, Eisenhaber F, MaurerStroh S, Sun T. RNAase-III enzyme Dicer maintains signaling pathways for differentiation and survival in mouse cortical neural stem cells. J Cell Sci. 2010;123(Pt 4):586-94

53. Ciaudo C, Jay F, Okamoto I, Chen CJ, Sarazin A, Servant N, Barillot E, Heard E, Voinnet O. RNAi-dependent and independent control of LINE1 accumulation and mobility in mouse embryonic stem cells. PLoS Genet. 2013;9(11):e1003791.

54. Muotri AR, Chu VT, Marchetto MC, Deng W, Moran JV, Gage FH. Somatic mosaicism in neuronal precursor cells mediated by L1 retrotransposition. Nature. 2005;435(7044):903-10.

55. Coufal NG, Garcia-Perez JL, Peng GE, Yeo GW, Mu Y, Lovci MT, Morell M, O'Shea KS, Moran JV, Gage FH. L1 retrotransposition in human neural progenitor cells. Nature. 2009;460(7259):1127-31

56. Baillie JK, Barnett MW, Upton KR, Gerhardt DJ, Richmond TA, De Sapio F, Brennan PM, Rizzu P, Smith S, Fell M, et al. Somatic retrotransposition alters the genetic landscape of the human brain. Nature. 2011;479(7374):534-7.

57. Lathe R, Harris A. Differential display detects host nucleic acid motifs altered in scrapie-infected brain. J Mol Biol. 2009;392(3):813-22.

58. Muotri AR, Marchetto MC, Coufal NG, Oefner R, Yeo G, Nakashima K, Gage FH. L1 retrotransposition in neurons is modulated by MeCP2. Nature. 2010;468(7322):443-6.

59. Jeong BH, Lee YJ, Carp RI, Kim YS. The prevalence of human endogenous retroviruses in cerebrospinal fluids from patients with sporadic Creutzfeldt-Jakob disease. J Clin Virol Off Publ Pan Am Soc Clin Virol. 2010;47(2):136-42.

60. Coufal NG, Garcia-Perez JL, Peng GE, Marchetto MC, Muotri AR, Mu Y, Carson CT, Macia A, Moran JV, Gage FH. Ataxia telangiectasia mutated (ATM) modulates long interspersed element-1 (L1) retrotransposition in human neural stem cells. Proc Natl Acad Sci USA. 2011;108(51):20382-7.
61. Douville R, Liu J, Rothstein J, Nath A. Identification of active loci of a human endogenous retrovirus in neurons of patients with amyotrophic lateral sclerosis. Ann Neurol. 2011;69(1):141-51.

62. Kaneko H, Dridi S, Tarallo V, Gelfand BD, Fowler BJ, Cho WG, Kleinman ME, Ponicsan SL, Hauswirth WW, Chiodo VA, et al. DICER1 deficit induces Alu RNA toxicity in age-related macular degeneration. Nature. 2011:471(7338):325-30.

63. Tan H, Qurashi A, Poidevin M, Nelson DL, Li H, Jin P. Retrotransposon activation contributes to fragile $X$ premutation rCGG-mediated neurodegeneration. Hum Mol Genet. 2012;21(1):57-65.

64. Li W, Jin Y, Prazak L, Hammell M, Dubnau J. Transposable elements in TDP43-mediated neurodegenerative disorders. PLoS One. 2012;7(9):e44099.

65. Li W, Prazak L, Chatterjee N, Gruninger S, Krug L, Theodorou D, Dubnau J. Activation of transposable elements during aging and neuronal decline in Drosophila. Nat Neurosci. 2013;16(5):529-31.

66. Zhao C, Teng EM, Summers RG Jr, Ming GL, Gage FH. Distinct morphological stages of dentate granule neuron maturation in the adult mouse hippocampus. J Neurosci Off J Soc Neurosci. 2006;26(1):3-11.

67. Tashiro A, Sandler VM, Toni N, Zhao C, Gage FH. NMDA-receptor-mediated, cell-specific integration of new neurons in adult dentate gyrus. Nature. 2006;442(7105):929-33.

68. Ray J, Gage FH. Differential properties of adult rat and mouse brain-derived neural stem/progenitor cells. Mol Cel Neurosci. 2006:31(3):560-73.

69. Ortega F, Costa MR, Simon-Ebert T, Schroeder T, Gotz M, Berninger B. Using an adherent cell culture of the mouse subependymal zone to study the behavior of adult neural stem cells on a single-cell level. Nat Protoc. 2011;6(12):1847-59.

70. Merz K, Lie DC. Evidence that Doublecortin is dispensable for the development of adult born neurons in mice. PLoS One. 2013;8(5):e62693.

71. Zhu JY, Strehle M, Frohn A, Kremmer E, Hofig KP, Meister G, Adler H. Identification and analysis of expression of novel microRNAs of murine gammaherpesvirus 68. J Virol. 2010;84(19):10266-75.

\section{Submit your next manuscript to BioMed Central and take full advantage of:}

- Convenient online submission

- Thorough peer review

- No space constraints or color figure charges

- Immediate publication on acceptance

- Inclusion in PubMed, CAS, Scopus and Google Scholar

- Research which is freely available for redistribution

Submit your manuscript at 